\title{
Anti-FXa-Ila activity test in Asian and its potential role for drug adherence evaluation in patients with direct oral anticoagulants: a nationwide multi-center synchronization study
}

\author{
Zhiyan Liu ${ }^{1,2 \#}$, Qiufen Xie ${ }^{1 \#}$, Qian Xiang ${ }^{1,2}$, Hanxu Zhang ${ }^{1}$, Guangyan Mu ${ }^{1}$, Zinan Zhao ${ }^{3}$, \\ Taotao $\mathrm{Hu}^{4}$, Tingting $\mathrm{Wu}^{5}$, Na Wang ${ }^{6}$, Jinhua Zhang ${ }^{5}$, Yan Qian ${ }^{6}$, Shuang Zhou ${ }^{1}$, Zining Wang ${ }^{1}$, \\ Jie Jiang ${ }^{7}$, Yatong Zhang ${ }^{3}$, Hongtao Song ${ }^{4}$, Yimin Cui ${ }^{1,2}$
}

${ }^{1}$ Department of Pharmacy, Peking University First Hospital, Beijing, China; ${ }^{2}$ School of Pharmaceutical Sciences, Peking University Health Science Center, Beijing, China; ${ }^{3}$ Department of Pharmacy, Beijing Hospital, Beijing, China; ${ }^{4}$ Department of Pharmacy, 900 Hospital of the Joint Logistics Team, Fuzhou, China; ${ }^{5}$ Department of Pharmacy, Fujian Medical University Union Hospital, Fuzhou, China; ${ }^{6}$ Department of Pharmacy, The Second Affiliated Hospital of Chongqing Medical University, Chongqing, China; ${ }^{7}$ Department of Cardiology, Peking University First Hospital, Beijing, China

Contributions: (I) Conception and design: Y Cui, Q Xiang; (II) Administrative support: J Jiang, Y Zhang, H Song, J Zhang, Y Qian, Z Wang; (III) Provision of study materials or patients: Z Liu, Q Xie, Q Xiang, H Zhang, G Mu, Z Zhao, T Hu, T Wu, N Wang, S Zhou; (IV) Collection and assembly of data: Z Liu, Q Xie, Q Xiang, H Zhang, G Mu, Z Zhao, T Hu, T Wu, N Wang, S Zhou; (V) Data analysis and interpretation: Z Liu, Q Xie, H Zhang, Qian Xiang; (VI) Manuscript writing: All authors; (VII) Final approval of manuscript: All authors.

\#These authors contributed equally to this work.

Correspondence to: Yimin Cui, MD, PhD. Department of Pharmacy, Peking University First Hospital, No. 6, Dahongluochang Street, Xicheng District, Beijing 100034, China. Email: cui.pharm@pkufh.com.

Background: The data of anti-FXa-IIa activity detection in Asian population is insufficient, and its potential role for drug adherence evaluation in patients with direct oral anticoagulants (DOACs) remains unclear. This study carried out multi-center anti-FXa-IIa activity detection in Asian, aiming to explore its applicability in Asian population and find its role in adherence evaluation.

Methods: We assessed patients' self-reported adherence using the Morisky, Green, and Levine Adherence Scale (MGLS) from six hospitals. Plasma samples were collected for peak and trough concentration determination, and anti-FXa-IIa chromogenic assay was conducted using rivaroxaban/dabigatran calibrators and controls. Multivariate logistic regression models, covariate adjustment and spearman's two-tailed test were conducted in the data analysis. This study had been registered in clinical trials (NCT03666962).

Results: In total, 271 patients taking rivaroxaban $(n=149)$ or dabigatran $(n=122)$ were enrolled. Among the 271 patients assessed by MGLS questionnaire, 188 persons (69.4\%) showed high adherence, 77 persons (28.4\%) was in intermediate adherence group, and only 6 patients $(2.2 \%)$ had low adherence. Patients are more adherent dosed once daily of rivaroxaban compared to twice daily of dabigatran: $75.6 \%$ vs. $63.6 \%$. Anti-FXa-IIa activity had good linear correlation with routine coagulation indexes $(\mathrm{P}<0.001)$, but no significant association was found between drug adherence and anti-FXa-IIa activity $(\mathrm{P}>0.05)$.

Conclusions: This study confirms that anti-FXa-IIa activity detection based on target drug calibrations can be used as an effective index for pharmacodynamic evaluation in Asian population, but had limited value in drug adherence evaluation for DOACs. As the limited samples, these findings could serve as a hypothesisgenerating effort, and should be validated in further studies with larger sample sizes.

Keywords: Direct oral anticoagulants (DOACs); anti-FXa-IIa activity; drug adherence

Submitted Jun 13, 2020. Accepted for publication Sep 10, 2020.

doi: $10.21037 / \mathrm{cdt}-20-564$

View this article at: http://dx.doi.org/10.21037/cdt-20-564 


\section{Introduction}

Venous thromboembolism (VTE), and stroke in patients with atrial fibrillation remain a worldwide leading cause of morbidity and mortality (1). Anticoagulant therapy plays an important role in prevention and treatment of VTE, and prevention of stroke. The direct oral anticoagulants (DOACs), oral direct inhibitors of both thrombin and factor $\mathrm{Xa}$ are convenient for not requiring routine coagulation monitoring and are shown to be safe and effective for the primary and secondary preventions of stroke and systemic embolism (SE) in patients with non-valvular atrial fibrillation (NVAF) $(2,3)$.

Although DOACs' compliance is better than warfarin, there are still many individual differences in clinical application (4-6). DOACs have the characteristics of fast metabolism and short half-life, forgetting to take drugs after repeated administration will have great influence on its blood concentration (7-9). Drug adherence is defined as the patient chooses to appropriately follow prescriber's recommendations concerning medication intake (10), of which importance as a pivotal issue in medical management had increased (11). Lots of phase III random clinical trials of DOACs reported discontinuation rates ranged from $18 \%$ to $35 \%(2,12)$. Lower adherence to dabigatran was found to be associated with higher risk of mortality and stroke [hazard ratio $(\mathrm{HR})=1.07](13)$.

Thus, tools to evaluate medication adherence in some specific situations are needed to ensure efficacy and safety in patients treated with DOACs (14). The proportion of days covered (PDC), the Morisky Medication Adherence Scale, and drug concentrations are available method to assess adherence (15-17). Adherence scales have the potential to explore these aspects of adherence, however, there is a great subjective bias in self-report, and the objective evaluation index is more reliable in clinical application. Anti-FXa-IIa activity presents a good correlation with drug concentration $(\mathrm{r}=0.98, \mathrm{P}<0.001)(18)$, and is recommended for qualitative assessment of DOACs in the 2018 international council for standardization in hematology (ICSH) (19). However, its potential role for drug adherence evaluation in patients with DOACs remains unclear in China, and few hospitals conduct anti-FXa-IIa activity assay.

Stated thus, the data of anti-FXa-IIa activity detection in Asian population is insufficient, and its potential role for drug adherence evaluation in patients with DOACs remains unclear. This study carried out multi-center anti-FXa-IIa activity detection, aimed to explore its applicability in Asian population and find its role in adherence evaluation.

We present the following article in accordance with the MDAR reporting checklist (available at http://dx.doi. org/10.21037/cdt-20-564).

\section{Methods}

\section{Population}

We launched a nationwide multi-center synchronization study among six hospitals. Patients meeting the following inclusion criteria will be included in the study: (I) dabigatran or rivaroxaban was used for prevention of stroke and SE in adult patients with NVAF; (II) age $>18$ years old, unlimited for gender; (III) patients were conscious and able to understand and answer questions. Baseline data were recorded when patients were enrolled. The thromboembolic and bleeding risk for each patient was calculated using $\mathrm{CHA}_{2} \mathrm{DS}_{2}$-VASc and HAS-BLED score. Patients will be grouped according to the compliance assessment results. The screening flow chart of the study population is shown in Figure 1.

The research was conducted in adherence with the Declaration of Helsinki (64th WMA General Assembly, Fortaleza, Brazil, October 2013), and the Harmonized Tripartite Guideline for Good Clinical Practice from the International Conference on Harmonization. The multicenter study protocol was reviewed and approved by the Ethical Review Board of the Peking University First Hospital \{approval number 2018[136]\}, and was registered in clinical trials (NCT03666962). All patients enrolled gave their written informed consent prior to participation in the study.

\section{Drug adberence assessment}

The Morisky, Green, and Levine Adherence Scale (MGLS) was used to evaluate the medication adherence of dabigatran and rivaroxaban. Details of the MGLS questionnaire are given in Table S1. In MGLS scale, scores ranged from 0 to 4 and each of the four items was in a (yes/no) format. One point was scored for each positive response and zero points were given for a "no" answer. Thus, the lower the score, the higher adherence. Patients' adherence can be divided into three groups: a score of 0 indicated high adherence; a score of 1 or 2 illustrated intermediate adherence; and a score of 


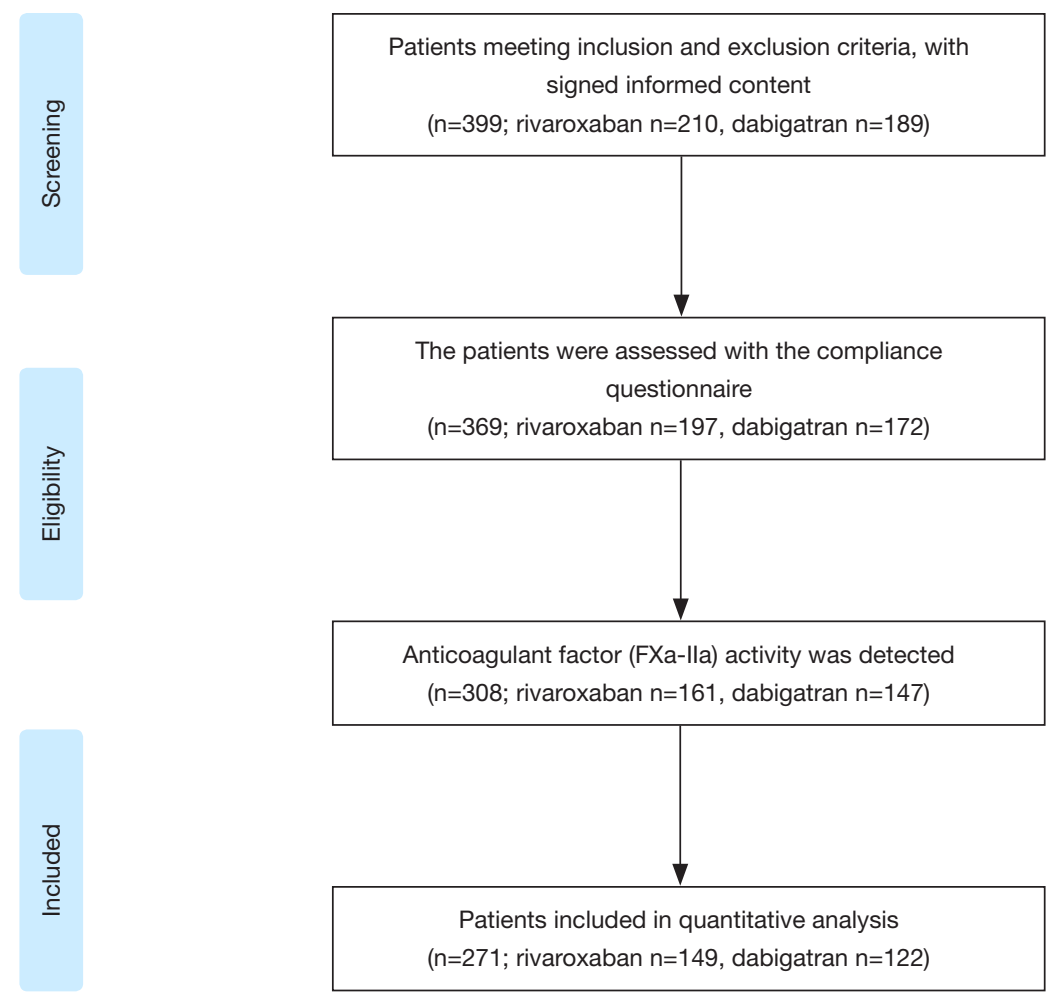

Figure 1 The screening flow chart of the study population.

3 or 4 indicated low adherence (20).

\section{Plasma sample collection and detection}

Plasma samples were collected for determination of peak and trough concentration. A plasma sample obtained $>10 \mathrm{~h}$ after the previous dabigatran dose or $>22 \mathrm{~h}$ after the previous rivaroxaban dose was considered for trough concentration. In this study, blood samples collected within average $2.19 \mathrm{~h}$ after dabigatran dose or $3.06 \mathrm{~h}$ after rivaroxaban dose intake were considered for peak concentration.

The anti-FXa-IIa chromogenic assay used rivaroxaban or dabigatran calibrators and controls (BIOPHEN Rivaroxaban/Dabigatran ${ }^{\circledR}$ Calibrator and Control, HYPHEN BioMed, Neuville sur Oise, France). All coagulation assays and dedicated tests based on antiFXa-IIa activity were performed using the Sysmex ${ }^{\circledR}$ CS2100i (Sysmex, Kobe, Japan) instrument with a validated application. Coagulation monitoring indexes, including activated partial thromboplastin time (APTT), prothrombin time (PT) were also detected for patients involved.

\section{Statistical analysis}

Statistical analyses were performed using the SPSS software, version 22.0 (SPSS Inc., Chicago, IL, USA). Numbers are presented as mean \pm standard deviation (SD) for continuous variables and as percentage for categorical variables in the tables. Associations between adherence groups and baseline patient characteristics were assessed using multivariate logistic regression models in the dabigatran and rivaroxaban sub-cohorts. Correlation between anti-FXa-IIa activity and medication adherence was tested by Spearman's twotailed test. Covariate adjustment of dosage and baseline was conducted using binary logistic analysis. Different doses were divided into groups, and logistics analysis was conducted in the form of covariates. The $\mathrm{P}$ value of 0.05 was considered significant in the study.

\section{Results}

\section{Demographic characteristics}

In total, 271 patients taking rivaroxaban $(n=149)$ or dabigatran $(n=122)$ were enrolled in the study. According 
Table 1 Baseline demographics and clinical characteristics of the study population

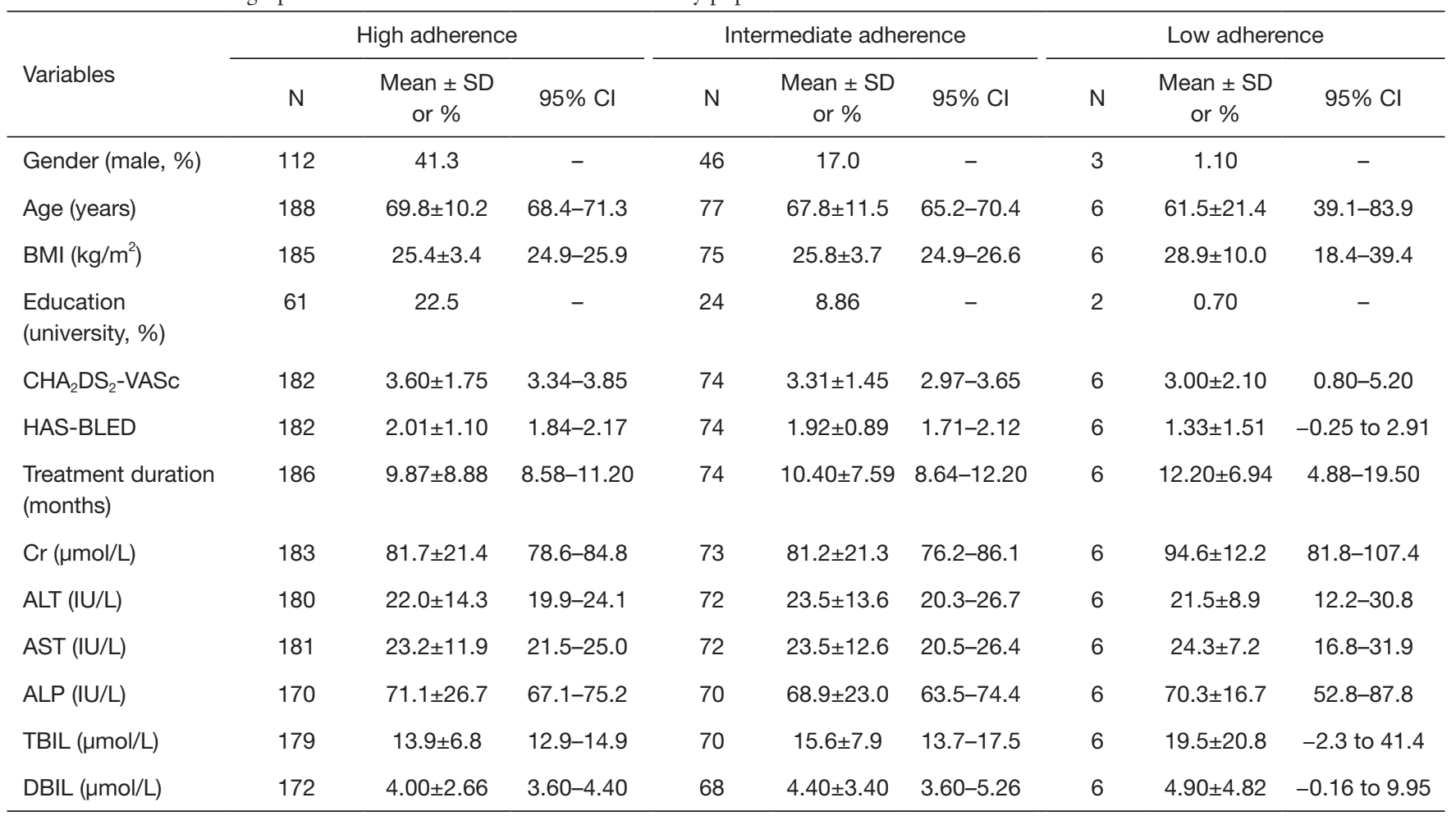

CHA2DS2-VASc: congestive heart failure, hypertension, 75 years of age and older, diabetes mellitus, previous stroke or transient ischemic attack, vascular disease, 65 to 74 years of age, female; HAS-BLED: hypertension, abnormal renal/liver function, stroke, bleeding history or predisposition, labile international normalized ratio, elderly, drugs/alcohol concomitantly. Cl, confidence interval; BMI, body mass index; $\mathrm{Cr}$, creatinine; ALT, alanine aminotransferase; AST, aspartate transaminase; ALP, alkaline phosphatase; TBIL, total bilirubin; DBIL, direct bilirubin; SD, standard deviation.

to the scores of MGLS, patients were divided into three groups: high, intermediate and low adherence group. Baseline demographics and clinical characteristics of the study population are provided in Table 1 . The total population average age was $69.1 \pm 10.9$ years old, body mass index (BMI) was $25.60 \pm 3.76 \mathrm{~kg} / \mathrm{m}^{2}$, and the $\mathrm{CHA}_{2} \mathrm{DS}_{2}$-VASc scores/ HAS-BLED scores are $3.50 \pm 1.68,1.97 \pm 1.06$ respectively. Associations between adherence groups and baseline patient characteristics were assessed using multivariate logistic regression models in the dabigatran and rivaroxaban subcohorts (Table S2). All patients had taken dabigatran or rivaroxaban for at least 1 month before initiation of the study. Blood was collected from patients receiving dabigatran $110 \mathrm{mg}$ twice daily or rivaroxaban 20 or $15 \mathrm{mg}$ once daily, and mean treatment duration was $10.10 \pm 8.48$ months in the study.

\section{Adherence assessment results}

Among the 271 patients assessed, 188 persons (69.4\%) showed high adherence, 77 persons $(28.4 \%)$ was in intermediate adherence group, and only 6 patients $(2.2 \%)$ had low adherence. Patients were more adherent dosed once daily compared to twice daily: high adherence of patients with rivaroxaban once daily dosing accounted for $75.6 \%$, with only $63.6 \%$ was found in dabigatran twice daily regimen $(\mathrm{P}=0.005)$. No low adherence patients were found in rivaroxaban once daily dosing regimen.

\section{Anti-FXa-IIa activity result}

Association between anti-FXa-IIa activity and coagulation indexes in peak and trough concentration was explored. In this study, APTT and PT are the main coagulation indicators, because TT is easy to exceed the detection limit. APTT and PT had good correlation with anti-FXaIIa activity $(\mathrm{P}<0.001$, Table 2$)$, indicating that anti-FXa-IIa activity can be an effect indexes of drug assessment.

Anti-FXa-IIa activity among different adherence 
Table 2 Association between anti-FXa-IIa activities and anticoagulation indexes in peak and trough concentration

\begin{tabular}{|c|c|c|}
\hline Anti-FXa-Ila activities & APTT & PT \\
\hline r & $0.640^{\star \star}$ & $0.696^{\star \star}$ \\
\hline$P$ & $5.95 \times 10^{-18}$ & $4.18 \times 10^{-22}$ \\
\hline $\mathrm{N}$ & 144 & 144 \\
\hline \multicolumn{3}{|c|}{ Rivaroxaban anti-Xa-trough } \\
\hline r & $0.368^{\star *}$ & $0.436^{\star \star}$ \\
\hline$P$ & $1.11 \times 10^{-5}$ & $1.25 \times 10^{-7}$ \\
\hline $\mathrm{N}$ & 135 & 135 \\
\hline \multicolumn{3}{|l|}{ Dabigatran anti-Ila-peak } \\
\hline $\mathrm{N}$ & 119 & 119 \\
\hline \multicolumn{3}{|c|}{ Dabigatran anti-lla-trough } \\
\hline r & $0.601^{\star \star}$ & $0.432^{\star \star}$ \\
\hline$P$ & $8.23 \times 10^{-13}$ & $1.19 \times 10^{-6}$ \\
\hline $\mathrm{N}$ & 117 & 117 \\
\hline
\end{tabular}

**, correlation is significant at the 0.01 level (2-tailed); ${ }^{*}$, correlation is significant at the 0.05 level (two-tailed). APTT, activated partial thromboplastin time; PT, prothrombin time; INR, international normalized ratio; TT, thrombin time; $r$, correlation coefficient.

groups in peak and trough concentration are summarized in Table 3. For rivaroxaban users, anti-FXa peak activities of 107 patients with good adherence was $269.10 \pm 12.20 \mathrm{ng} / \mathrm{mL}$, while intermediate adherence was $244.00 \pm 19.60 \mathrm{ng} / \mathrm{mL}$. The antiFXa trough activities in rivaroxaban patients were similar: $46.50 \pm 3.99$ vs. $45.20 \pm 5.74 \mathrm{ng} / \mathrm{mL}$ for high and intermediate adherence group. Dabigatran patients in the low adherence group had abnormal anti-FIIa trough activities $(70.10 \pm 33.70$ vs. $66.60 \pm 10.00 \mathrm{ng} / \mathrm{mL}$, higher than intermediate group patients), which might own to limited samples and greatly changed data. However, no significant association was found between drug adherence and anti-FXa-IIa peak and trough activities $(\mathrm{P}>0.05$, Table 3$)$.

In the baseline comparison, $\mathrm{CHA}_{2} \mathrm{DS}_{2}$-VASc and HASBLED scores were found significantly different among different adherence groups in dabigatran patients. Thus, covariate adjustment of baseline and dosage was conducted using binary logistic analysis. No significant association was found between anti-FIIa peak/trough activities and drug adherence after adjustment $(\mathrm{P}=0.718,0.962$, Table 4). After dose adjustment, anti-FXa activity of high adherence and intermediate groups were $269.10 \pm 12.10 \mathrm{vs}$.
$244.10 \pm 20.60 \mathrm{ng} / \mathrm{mL}$ in peak concentration, and $46.10 \pm 3.80$ vs. $46.50 \pm 6.98 \mathrm{ng} / \mathrm{mL}$ in trough concentration, without significant statistical difference found $(\mathrm{P}=0.576$ and 0.250 , Table 4).

\section{Discussion}

\section{Main findings}

This study confirms that anti-FXa-IIa activity detection based on target drug calibrations can be used as an effective index for pharmacodynamic evaluation in Asian population, at the same time, as an objective index, it is a good supplement to the compliance evaluation.

\section{Adherence on DOACs}

The absence of a need for routine plasma level monitoring means that DOACs patients are likely to be less frequently seen for follow-up compared with vitamin $\mathrm{K}$ antagonist patients. In our survey, most patients thought themselves had high adherence (86.3\%). However, only $69.4 \%$ person 
Table 3 Anti-FXa-IIa activities among different adherence groups in peak and trough concentration

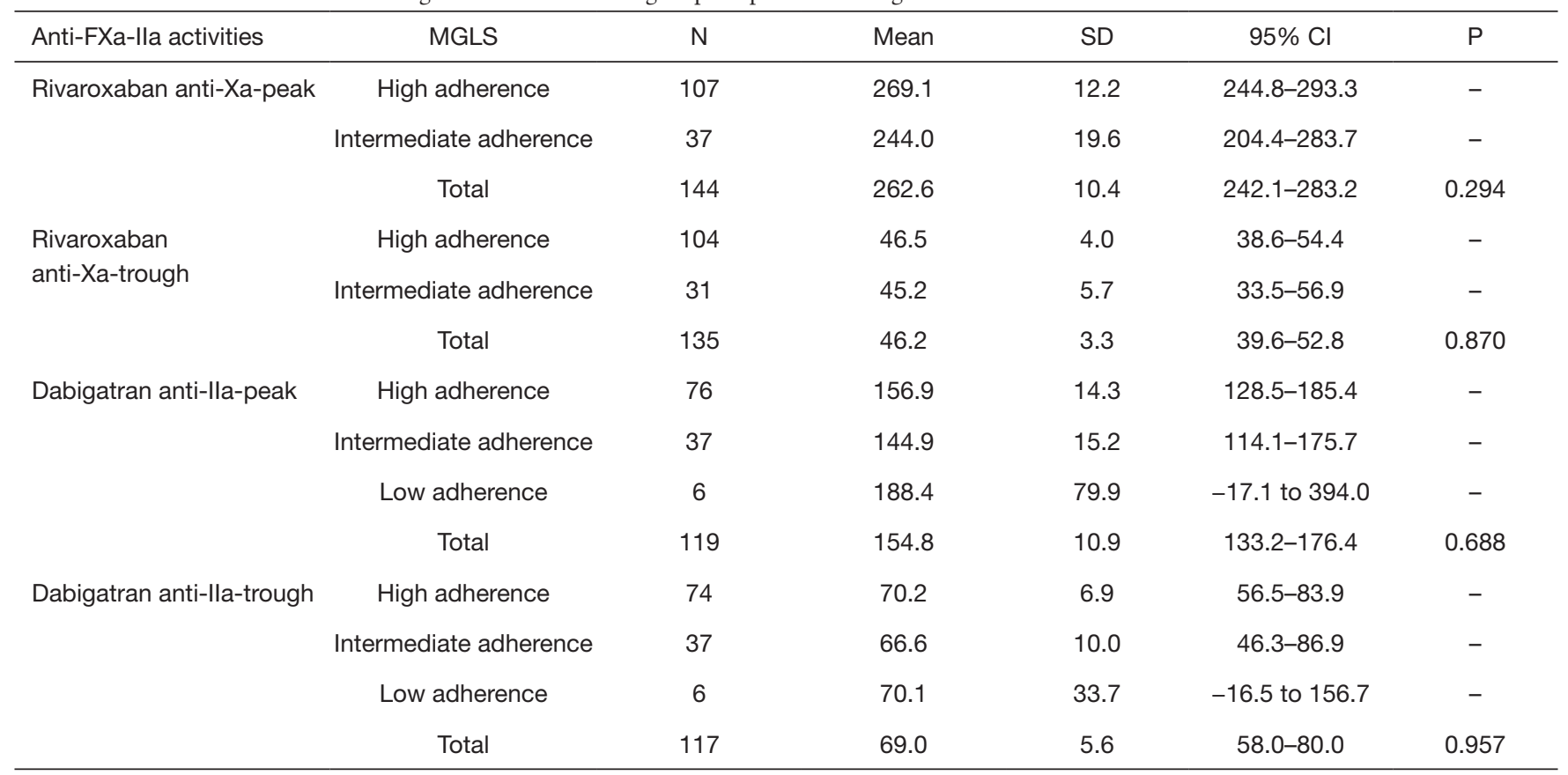

Unit of anti-FXa-Ila activities: ng/mL. MGLS, Morisky, Green, and Levine Adherence Scale; Cl, confidence interval; SD, standard deviation.

Table 4 Anti-FX/IIa activities among different adherence groups after adjustment in peak and trough concentration

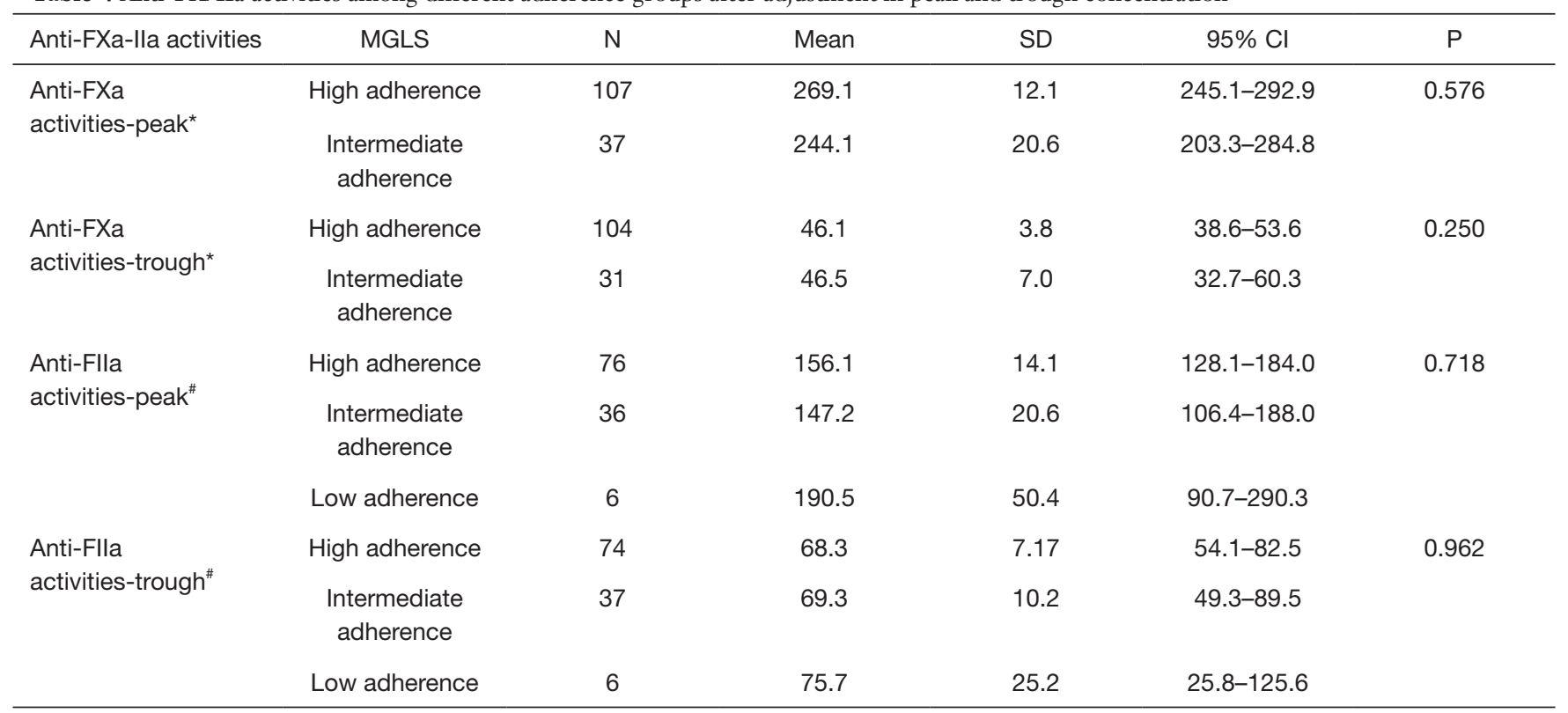

*, covariates appearing in the model are evaluated by dose; ", covariates appearing in the model are evaluated by CHA2DS2-VAS scores, and HAS-BLED scores. Unit of anti-FXa activities: $\mathrm{ng} / \mathrm{mL}$. MGLS, Morisky, Green, and Levine Adherence Scale; Cl, confidence interval; $\mathrm{SD}$, standard deviation. 
Table 5 Available real-world data that suggested patients' adherence to DOACs

\begin{tabular}{|c|c|c|c|c|c|c|}
\hline Study & Drugs & Methods & $\begin{array}{l}\text { Patients } \\
\text { included }\end{array}$ & $\begin{array}{l}\text { Adherence } \\
\text { percent (\%) }\end{array}$ & $\begin{array}{l}\text { Non- } \\
\text { adherence } \\
\text { percent (\%) }\end{array}$ & $\begin{array}{l}\text { Factors and outcomes associated with } \\
\text { adherence }\end{array}$ \\
\hline $\begin{array}{l}\text { Zalesak, } \\
2013(23)\end{array}$ & Dabigatran & Self-report & 3,370 & 74.07 & 25.93 & $\begin{array}{l}\text { Patients with a low-to-moderate risk of stroke } \\
\text { or with a higher bleed risk had a higher } \\
\text { likelihood of non-persistence }(H R, 1.37 \text {; } \\
P<0.001 \text {; and } H R, 1.24 ; P=0.016)\end{array}$ \\
\hline Yao, 2016 (25) & DOACs & PDC & 26,471 & 47.50 & 52.50 & $\begin{array}{l}\text { Adherence to therapy appears to be most } \\
\text { important in patients with CHA2DS2- } \\
\text { VASc score } \geq 2 \text {, whereas the benefits of } \\
\text { anticoagulation may not outweigh the harms } \\
\text { in patients with CHA2DS2-VASc score } 0 \text { or } 1\end{array}$ \\
\hline Shore, 2015 (26) & Dabigatran & PDC & 5,376 & 72.21 & 27.79 & $\begin{array}{l}\text { The proportion of adherent patients was } \\
\text { higher at sites performing appropriate } \\
\text { selection ( } 75 \% \text { vs. } 69 \%) \text {, education ( } 76 \% \text { vs. } \\
66 \%) \text {, and monitoring ( } 77 \% \text { vs. } 65 \%)\end{array}$ \\
\hline $\begin{array}{l}\text { Sørensen, } \\
2017 \text { (28) }\end{array}$ & DOACs & PDC & 19,952 & 43.34 & 56.66 & $\begin{array}{l}\text { Poor adherence of DOACS for both short- and } \\
\text { long-periods leaves the patient at higher risk } \\
\text { of thrombosis }\end{array}$ \\
\hline $\begin{array}{l}\text { Schulman, } \\
2013 \text { (15) }\end{array}$ & Dabigatran & PDC & 103 & 88.35 & 11.65 & $\begin{array}{l}\text { Routine feedback from the pharmacies } \\
\text { could inform the physician to improve the } \\
\text { anticoagulant management }\end{array}$ \\
\hline
\end{tabular}

DOACs, direct oral anticoagulant; HR, hazard ratio; PDC, proportion of days covered.

showed high adherence among the 271 patients assessed by MGLS questionnaire, suggesting that authenticity of self-reported still needs to be verified. Available real-world data suggested adherence to DOACs ranged from $43 \%$ to $88 \%$ depending on the setting and definition (21-28), as are summarized in Table 5. Emren et al. [2018] (21) found that non-adherence had related to stroke $(5.6 \%$ vs. $2.5 \%$, $\mathrm{P}<0.001)$ and minor $(21.2 \%$ vs. $11.1 \%, \mathrm{P}<0.001)$ and major (6.1\% vs. 3.7\%, $\mathrm{P}=0.004)$ bleeding rates than adherences. Patient education on the need for oral anticoagulation therapy and the importance of strict adherence is still important (29-31). 


\section{DOACs monitor}

Many technological aids and approaches are employed to enhance adherence: a patient anticoagulation card, group sessions, the day-marked blister pack format; medication boxes (conventional or with electronic verification of intake); smartphone applications with reminders and/or SMS messages to alert the patient about the next intake some even requiring confirmation that the dose has been taken (32). Each method with specific advantages and limitations, as was described by Vrijens et al. (33). As most patients treated with DOAC were elderly persons (69.1 \pm 10.9 years old), they were not good at using electronic devices to remind themselves. Elders tend to forget things easily, thus adherence becomes hard to guarantee. In this case, effective methods of assessing adherence are very important for drug treatment and disease management.

Anti-FXa-IIa activity has good linear correlation with routine coagulation indexes $(\mathrm{P}<0.001)$, indicating that antiFXa-IIa activity can be employed for the rapid assessment (only $5 \mathrm{~min}$ ) of dabigatran or rivaroxaban's anticoagulant activity in Asian population. For dabigatran users, the mean peak anti-FXa-IIa activity was $154.8 \pm 10.9 \mathrm{ng} / \mathrm{mL}$ in the study. Moreover, inter-laboratory coefficient of variations and biases were found below $18 \%$ and $8 \%$ for dabigatran/ rivaroxaban calibrated assays (Hyphen-Biomed) in 30 hemostasis laboratories (34), thus, this result can also be used as a reference for different laboratory tests in Asian area. Rapid and accurate laboratory assessment of drug exposure and anticoagulant effect may help clinicians in emergencies as well as in special situations $(35,36)$. For patients with multiple factors that interfere with the pharmacokinetics of a given DOAC (e.g., uncontrolled cancer patients receiving therapy for malignancies), anti-FXa-IIa activity assay could be to verify that plasma levels are within the "on treatment" range, considered the different "on therapy" range for samples taken at peak or at trough levels (37).

\section{Clinical consideration}

Adherence scales have the potential to explore these aspects of adherence, however, there is a great subjective bias in self-report, and the objective evaluation index is more reliable in clinical application. Anti-FXa-IIa activity presents a good correlation with drug concentration, and is recommended for qualitative assessment of DOACs in the 2019 ICSH. As a hypothesis-generating effort, this study suggested that anti-FXa-IIa activity detection had limited value in drug adherence evaluation for DOACs with the limited samples. However, as an objective index, antiFXa-IIa activity detection can be a good supplement to the compliance evaluation.

\section{Strengths and limitations}

As a preliminary exploration, we included 271 patients using DOACs to carry out multi-center anti-FXa-IIa activity detection, aimed to explore its applicability in Asian population and find its role in adherence evaluation.

There are several limitations in the study. (I) Owing to the inclusion criteria and exclusion criteria of the study in hospital, the number of enrolled patients was limited. (II) The study only carried out a blood sample collection and detection of patients after medication. (III) Other recommended indexes of laboratory monitoring, such as diluted thrombin time (dTT), ecarin clotting time (ECT) for dabigatran etc. were not including in this study.

\section{Conclusions}

This study confirms that anti-FXa-IIa activity detection based on target drug calibrations can be used as an effective index for pharmacodynamic evaluation in Asian population, but had limited value in drug adherence evaluation for DOACs. As the limited samples, these findings could serve as a hypothesis-generating effort, and should be validated in further studies with larger sample sizes.

\section{Acknowledgments}

Funding: This study was supported by grants from the National Key R\&D Program of China (No. 2016YFC0904900), National Natural Science Foundation of China (No. 81872940 and No. 81973395), Beijing Natural Science Foundation (No. 7171012), and National Science and Technology Major Projects for "Major New Drugs Innovation and Development" (No. 2017ZX09304028 and No. 2018ZX09201014).

\section{Footnote}

Reporting Checklist: The authors have completed the MDAR reporting checklist. Available at http://dx.doi.org/10.21037/ cdt-20-564

Data Sharing Statement: Available at http://dx.doi. 
org/10.21037/cdt-20-564

Conflicts of Interest: All authors have completed the ICMJE uniform disclosure form (available at http://dx.doi. org/10.21037/cdt-20-564). The authors have no conflicts of interest to declare.

Ethical Statement: The authors are accountable for all aspects of the work in ensuring that questions related to the accuracy or integrity of any part of the work are appropriately investigated and resolved. The research was conducted in adherence with the Declaration of Helsinki (64th WMA General Assembly, Fortaleza, Brazil, October 2013), and the Harmonized Tripartite Guideline for Good Clinical Practice from the International Conference on Harmonization. The multicenter study protocol was reviewed and approved by the Ethical Review Board of the Peking University First Hospital \{approval number 2018[136]\}, and was registered in clinical trials (NCT03666962). All patients enrolled gave their written informed consent prior to participation in the study.

Open Access Statement: This is an Open Access article distributed in accordance with the Creative Commons Attribution-NonCommercial-NoDerivs 4.0 International License (CC BY-NC-ND 4.0), which permits the noncommercial replication and distribution of the article with the strict proviso that no changes or edits are made and the original work is properly cited (including links to both the formal publication through the relevant DOI and the license). See: https://creativecommons.org/licenses/by-nc-nd/4.0/.

\section{References}

1. Patel MR, Mahaffey KW, Garg J, et al. Rivaroxaban versus warfarin in nonvalvular atrial fibrillation. $\mathrm{N}$ Engl J Med 2011;365:883-91.

2. Connolly SJ, Ezekowitz MD, Yusuf S, et al. Dabigatran versus warfarin in patients with atrial fibrillation. $\mathrm{N}$ Engl J Med 2009;361:1139-51.

3. Schulman S, Kearon C, Kakkar AK, et al. Dabigatran versus warfarin in the treatment of acute venous thromboembolism. N Engl J Med 2009;361:2342-52.

4. Antovic JP, Skeppholm M, Eintrei J, et al. Evaluation of coagulation assays versus LC-MS/MS for determinations of dabigatran concentrations in plasma. Eur J Clin Pharmacol 2013;69:1875-81.

5. Skeppholm M, Al-Aieshy F, Berndtsson M, et al. Clinical evaluation of laboratory methods to monitor apixaban treatment in patients with atrial fibrillation. Thromb Res 2015;136:148-53.

6. Reilly PA, Lehr T, Haertter S, et al. The effect of dabigatran plasma concentrations and patient characteristics on the frequency of ischemic stroke and major bleeding in atrial fibrillation patients: the RE-LY Trial (Randomized Evaluation of LongTerm Anticoagulation Therapy). J Am Coll Cardiol 2014;63:321-8.

7. Coppens M, Eikelboom JW, Gustafsson D, et al. Translational success stories development of direct thrombin inhibitors. Circ Res 2012;111:920-9.

8. Garcia D, Barrett YC, Ramacciotti E, et al. Laboratory assessment of the anticoagulant effects of the next generation of oral anticoagulants, J Thromb Haemost 2013;11:245-52.

9. Kubitza D, Perzborn E, Berkowitz SD. The discovery of rivaroxaban: translating preclinical assessments into clinical practice. Front Pharmacol 2013;4:145.

10. Lam WY, Fresco P. Medication Adherence Measures: An Overview. Biomed Res Int 2015;2015:217047.

11. McWilliams JM, Najafzadeh M, Shrank WH, et al. Association of Changes in Medication Use and Adherence with Accountable Care Organization Exposure in Patients with Cardiovascular Disease or Diabetes. JAMA Cardiol 2017;2:1019-23.

12. Giugliano RP, Ruff CT, Braunwald E, et al. Edoxaban versus warfarin in patients with atrial fibrillation. $\mathrm{N}$ Engl J Med 2013;369:2093-104.

13. Borne RT, O'Donnell C, Turakhia MP, et al. Adherence and outcomes to direct oral anticoagulants among patients with atrial fibrillation: findings from the veterans' health administration. BMC Cardiovasc Disord 2017;17:236.

14. Vrijens B, Urquhart J. From monitoring to vigilance about patient adherence to new oral anticoagulants. Europace 2014;16:149.

15. Schulman S, Shortt B, Robinson M, et al. Adherence to anticoagulant treatment with dabigatran in a real-world setting. J Thromb Haemost 2013;11:1295-9.

16. Coleman CI, Tangirala M, Evers T. Medication adherence to rivaroxaban and dabigatran for stroke prevention in patients with non-valvular atrial fibrillation in the United States. Int J Cardiol 2016;212:171-3.

17. Castellucci LA, Shaw J, van der Salm K, et al. Selfreported adherence to anticoagulation and its determinants using the Morisky medication adherence scale. Thromb Res 2015;136:727-31. 
18. Derogis PB, Sanches LR, de Aranda VF, et al. Determination of rivaroxaban in patient's plasma samples by anti-Xa chromogenic test associated to High Performance Liquid Chromatography tandem Mass Spectrometry (HPLC-MS/MS). PLoS One 2017;12:e0171272.

19. Gosselin RC, Adcock DM, Bates SM, et al. International Council for Standardization in Haematology (ICSH) Recommendations for Laboratory Measurement of Direct Oral Anticoagulants. Thromb Haemost 2018;118:437-50.

20. Morisky DE, Green LW, Levine DM. Concurrent and predictive validity of a self-reported measure of medication adherence. Med Care 1986;24:67-74.

21. Emren SV, Şenöz O, Bilgin M, et al. Drug Adherence in Patients with Nonvalvular Atrial Fibrillation Taking NonVitamin K Antagonist Oral Anticoagulants in Turkey: NOAC-TR. Clin Appl Thromb Hemost 2018;24:525-31.

22. Beyer-Westendorf J, Förster K, Ebertz F, et al. Drug persistence with rivaroxaban therapy in atrial fibrillation patients-results from the Dresden non-interventional oral anticoagulation registry. Europace 2015;17:530-8.

23. Zalesak M, Siu K, Francis K, et al. Higher persistence in newly diagnosed nonvalvular atrial fibrillation patients treated with dabigatran versus warfarin. Circ Cardiovasc Qual Outcomes 2013;6:567-74.

24. Gorst-Rasmussen A, Skjøth F, Larsen TB, et al. Dabigatran adherence in atrial fibrillation patients during the first year after diagnosis: a nationwide cohort study. J Thromb Haemost 2015;13:495-504.

25. Yao X, Abraham NS, Alexander GC, et al. Effect of Adherence to Oral Anticoagulants on Risk of Stroke and Major Bleeding Among Patients with Atrial Fibrillation. J Am Heart Assoc 2016;5:e003074.

26. Shore S, Ho PM, Lambert-Kerzner A, et al. Site-level variation in and practices associated with dabigatran adherence. JAMA 2015;313:1443-50.

27. Brown JD, Shewale AR, Talbert JC. Adherence to Rivaroxaban, Dabigatran, and Apixaban for Stroke Prevention in Incident, Treatment-Naïve Nonvalvular Atrial Fibrillation. J Manag Care Spec Pharm 2016;22:1319-29.

28. Sørensen R, Jamie Nielsen B, Langtved Pallisgaard J, et al. Adherence with oral anticoagulation in non-valvular atrial fibrillation: a comparison of vitamin $\mathrm{K}$ antagonists and non-vitamin K antagonists. Eur Heart J Cardiovasc Pharmacother 2017;3:151-6.

29. Lane DA, Aguinaga L, Blomstrom-Lundqvist C, et al. Cardiac tachyarrhythmias and patient values and preferences for their management: the European Heart Rhythm Association (EHRA) consensus document endorsed by the Heart Rhythm Society (HRS), Asia Pacific Heart Rhythm Society (APHRS), and Sociedad Latinoamericana de Estimulacion Cardiaca y Electrofisiologia (SOLEACE). Europace 2015;17:1747-69.

30. Heidbuchel H, Berti D, Campos M, et al. Implementation of non-vitamin $\mathrm{K}$ antagonist oral anticoagulants in daily practice: the need for comprehensive education for professionals and patients. Thromb J 2015;13:22.

31. Lane DA, Barker RV, Lip GY. Best practice for atrial fibrillation patient education. Curr Pharm Des 2015;21:533-43.

32. Guo Y, Chen Y, Lane DA, et al. Mobile health technology for atrial fibrillation management integrating decision support, education, and patient involvement: MAF App Trial. Am J Med 2017;130:1388-1396.e6.

33. Vrijens B, Heidbuchel H. Non-vitamin K antagonist oral anticoagulants: considerations on once- vs. twicedaily regimens and their potential impact on medication adherence. Europace 2015;17:514-23.

34. Gouin-Thibault I, Freyburger G, de Maistre E, et al. Evaluation of dabigatran, rivaroxaban and apixaban targetspecific assays in a multicenter French study. Thromb Res 2017;158:126-33.

35. van Ryn J, Stangier J, Haertter S, et al. Dabigatran etexilate--a novel, reversible, oral direct thrombin inhibitor: interpretation of coagulation assays and reversal of anticoagulant activity. Thromb Haemost 2010;103:1116-27.

36. Godier A, Dincq AS, Martin AC, et al. Predictors of pre-procedural concentrations of direct oral anticoagulants: a prospective multicentre study. Eur Heart J 2017;38:2431-9.

37. Steffel J, Verhamme P, Potpara TS, et al. The 2018 European Heart Rhythm Association Practical Guide on the use of non-vitamin $\mathrm{K}$ antagonist oral anticoagulants in patients with atrial fibrillation. Eur Heart J 2018;39:1330-93.

Cite this article as: Liu Z, Xie Q, Xiang Q, Zhang H, Mu G, Zhao Z, Hu T, Wu T, Wang N, Zhang J, Qian Y, Zhou S, Wang Z, Jiang J, Zhang Y, Song H, Cui Y. Anti-FXa-IIa activity test in Asian and its potential role for drug adherence evaluation in patients with direct oral anticoagulants: a nationwide multi-center synchronization study. Cardiovasc Diagn Ther 2020;10(5):1293-1302. doi: 10.21037/cdt-20-564 
Supplementary

Table S1 Details of the Morisky, Green, and Levine Adherence Scale (MGLS) questionnaire

\begin{tabular}{lll}
\hline Number & Questions & Answers \\
\hline 1 & Do you ever forget to take your NOACs? & Yes or no \\
2 & Do you ever have problems remembering to take your NOACs? & Yes or no \\
3 & When you feel better, do you sometimes stop taking your NOACs? & Yes or no \\
4 & Sometimes if you feel worse when you take your NOACs, do you stop taking it? & Yes or no \\
\hline
\end{tabular}

In this scale, scores gained from the MGLS ranged from 0 to 4 and each of the four items was in a (yes/no) format. One point was scored for each positive response, one point was given for a "yes" answer, and zero points were given for a "no" answer. So, the lower the score, the more adherence, since the four questions were negatively coded items. A score of 0 indicated high adherence; a score of 1 or 2 illustrated intermediate adherence; and a score of 3 or 4 indicated low adherence. 
Table S2 Baseline demographics and clinical characteristics of population

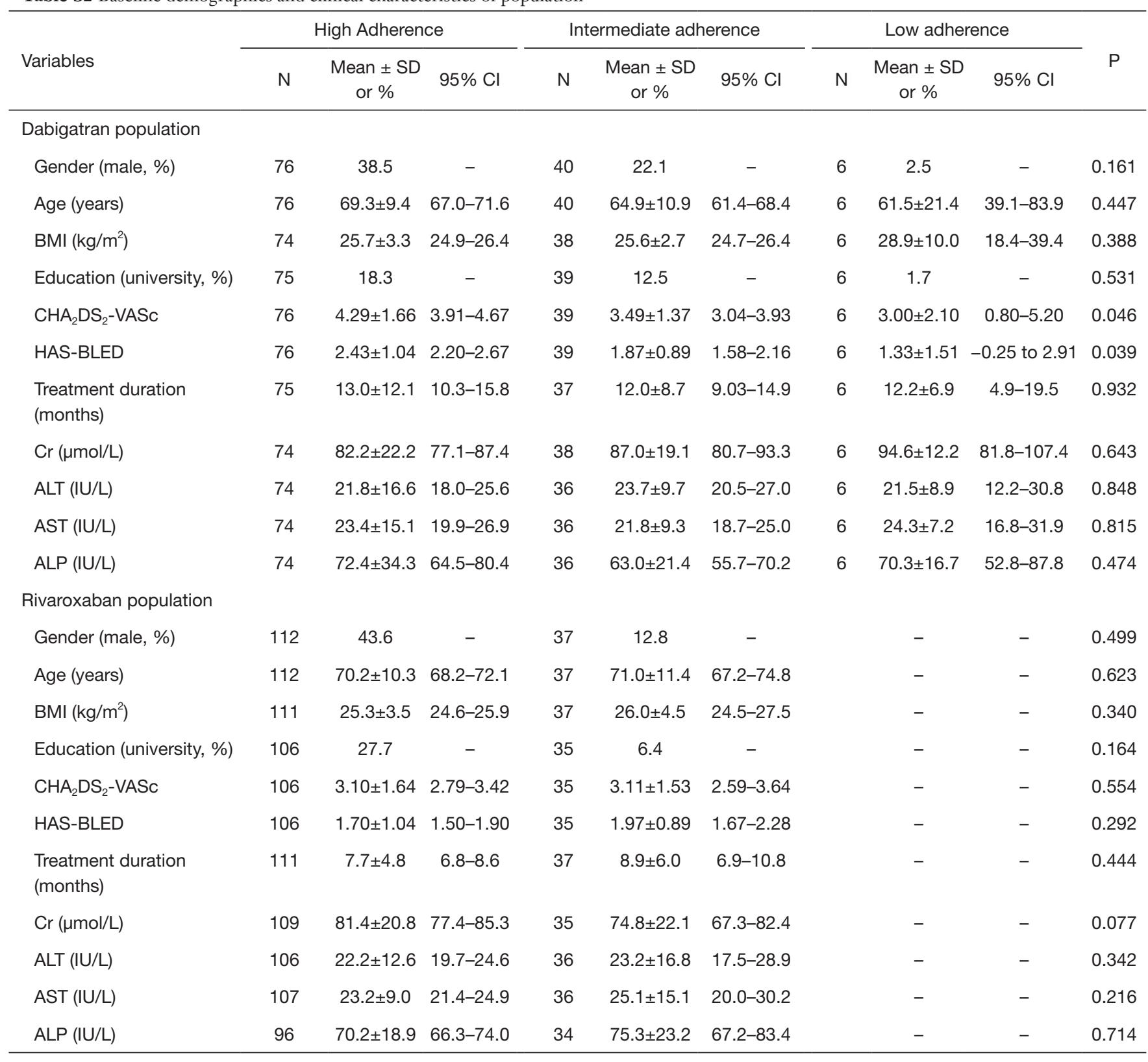

Associations between adherence groups and baseline patient characteristics were assessed using multivariate logistic regression models in the dabigatran and rivaroxaban sub-cohorts. CHA2DS2-VASc: congestive heart failure, hypertension, 75 years of age and older, diabetes mellitus, previous stroke or transient ischemic attack, vascular disease, 65 to 74 years of age, female; HAS-BLED: hypertension, abnormal renal/liver function, stroke, bleeding history or predisposition, labile international normalized ratio, elderly, drugs/alcohol concomitantly. Cl, confidence interval; BMI, body mass index; $\mathrm{Cr}$, creatinine; ALT, alanine aminotransferase; AST, aspartate transaminase; ALP, alkaline phosphatase; TBIL, total bilirubin; DBIL, direct bilirubin; SD, standard deviation. 